\title{
Estimativas da Produção de Leite por Vacas Holandesas Mestiças, Segundo o Sistema CNCPS, em Dietas Contendo Cana-de-Açúcar com Diferentes Valores Nutritivos
}

\author{
Alberto Magno Fernandes ${ }^{4}$, Augusto César de Queiroz ${ }^{1}$, Rogério de Paula Lana ${ }^{2}$, \\ José Carlos Pereira ${ }^{1}$, Luciano da Silva Cabral ${ }^{4}$, Andréa Vittori ${ }^{4}$, Elzânia Sales Pereira ${ }^{3}$
}

RESUMO - O objetivo do presente estudo foi usar os dados observados sobre as variações nos teores da fibra em detergente neutro (FDN), lignina e das frações de carboidratos e das correspondentes taxas de degradação de 15 variedades de cana-de-açúcar, para avaliar a disponibilidade destes nutrientes em promover produção de leite de vacas holandesas mestiças, usando o sistema CNCPS. Um suplemento nutricional composto de silagem de milho, caroço de algodão, farelo de soja e uréia foi usado para complementar as exigências nutricionais destes animais na produção de $10 \mathrm{~kg}$ de leite diário. Os valores utilizados para predizer as respostas na produção de leite foram: FDN (\%MS) - 40, 50 e 60, lignina (\%FDN) 10,14 e 18, taxas de digestão (\%/h) dos carboidratos não fibrosos (CNF) - 10,20 e 30 e taxa de digestão $(\% / h)$ dos carboidratos fibrosos $(\mathrm{CF})$ - 1, 2,5 e 4. A cana-de-açúcar, quando usada como principal volumoso da dieta, acarretou redução na ingestão de matéria seca e energia, limitando a produção de leite destes animais. A predição da quantidade de leite que poderia ser produzida em função da quantidade de energia metabolizável (EM), fornecida pela dieta, decresceu $24 \%$, quando o teor de FDN aumentou de 40 para 60\%, para um percentual de 14\% de lignina. Também houve acréscimo de $14 \%$ na produção de leite, quando a taxa de digestão dos CF aumentou de 1 para 2,5\%/h. Embora as variações nos teores de FDN e lignina e nas taxas de digestão dos carboidratos, das variedades de cana-de-açúcar, tenham promovido grande efeito sobre a produção de leite das vacas mestiças, torna-se necessária a validação destes resultados.

Palavras-chave: cana-de-açúcar, produção de leite, simulação, vacas mestiças

\section{Estimates of the Milk Production by Crossbred Holstein Cows, in Accordance to CNCPS System, in Diets Containing Sugar Cane with Different Nutritive Values}

\begin{abstract}
The objective of the present study was to use the observed data on the changes of the neutral detergent fiber (NDF), lignin and carbohydrate fractions and of the related degradation rates of 15 sugar cane varieties, to evaluate this nutrient availability in promoting the milk production of the crossbred Holstein cows using the CNCPS system. A concentrate supplement compose by corn silage, whole cottonseed and soybean meal and urea was used to attend the nutritional requirement of this animals to produce $10 \mathrm{~kg}$ of daily milk. The values used to predict the response in the milk production were: NDF (\%DM) - 40,50 and 60, lignin (\%NDF) 10,14 and 18 , digestion rates $(\% / \mathrm{h})$ of the non fiber carbohydrates (NFC) - 10,20 and 30 and digestion rate $(\% / \mathrm{h})$ of the fiber carbohydrates (FC) - 1, 2,5 and 4. The sugar cane, when used as main forage in the diet, caused a reduction in the dry matter intake and energy, limiting the milk production of these animals. The prediction of the amount of milk that could be produced in function of the amount of energy metabolizable (ME), supplied by the diet, decreased 24\% when the FDN content increased from 40 to $60 \%$, for a $14 \%$ of lignin. There was also an increment of $14 \%$ in the milk production when the FC digestion rate increased from 1 to $2,5 \% / \mathrm{h}$. Although the changes in the of NDF and lignin contents and in the carbohydrate digestion rates of the sugar cane varieties, have promoted a great effect on the crossbred Holstein cows milk production, it is necessary to validate these results.
\end{abstract}

Key Words: crossbred Holstein cows, milk production, simulation, sugar cane

\section{Introdução}

A grande maioria dos produtores de leite, principalmente os que utilizam vacas mestiças, faz uso da cana-de-açúcar (Saccharum spp) como principal volumoso da dieta no período que compreende a estação de seca. A cana-de-açúcar possui algumas características que têm justificado a sua escolha como recurso forrageiro, dentre elas, elevada produção por unidade de área cultivada, cultivo relativamente fácil, baixo custo por unidade de matéria seca produzida e coincidência do período de sua maior disponibilidade com o período de escassez de forragem na forma de pasto.

\footnotetext{
1 Professor titular do DZO-UFV, Bolsista do CNPq. E.mail: aqueiroz@ufv.br; jearper@mail.ufv.br

2 Professor Adjunto do DZO-UFV. E.mail: rlana@mail.ufv.br

3 Professor da UNEOESTE. E.mail: elzanea@unioeste.br

4 Estudantes de Pós-graduação - Nível Doutorado - DZO - UFV, Bolsista CAPES. E.mail: amagno@alunos.ufv.br; avittori@alunos.ufv.br
} 
Outra vantagem de se utilizar a cana-de-açúcar como recurso forrageiro constitui-se no fato de seu valor nutritivo manter-se praticamente constante por um período de tempo relativamente prolongado, sendo os melhores valores obtidos com intervalos de cortes de 12 a 18 meses, contrastando com outras gramíneas tropicais (PRESTON, 1986). Porém, a cana-de-açúcar, como alimento para ruminantes, apresenta limitações de ordem nutricional, devido aos baixos teores de proteína e minerais e ao alto teor de fibra de baixa degradação ruminal (PATE, 1977; LENG, 1988), causando baixa produtividade animal, quando se fornecem dietas com elevada proporção desse alimento.

Em termos nutricionais, os carboidratos podem ser classificados como carboidratos não-fibrosos (CNF) e fibrosos (CF). Os primeiros são representados pelos açúcares solúveis, pelo amido e pela pectina, os quais são completamente disponíveis no trato grastrintestinal (TGI). Os CF, representados pela celulose e hemicelulose, juntamente com a lignina, são incompletamente disponíveis e ocupam espaço no TGI (MERTENS, 1997). Os CNF apresentam disponibilidade constante entre os alimentos (cerca de 98\%); entretanto, os CF apresentam disponibilidade muito variável entre e dentre os alimentos, representando a fração que mais afeta a disponibilidade de energia dos alimentos (VAN SOEST, 1994). A grande variação dos teores de CF e CNF e a disponibilidade dos CF observada na cana-de-açúcar, em função das variedades e da idade de corte, pode causar respostas variadas na produção de leite, o que justifica o uso de sistemas de adequação de dietas para predizer a produção de leite pelas vacas recebendo quantidades elevadas desta forragem.

Atualmente, os sistemas de avaliação de alimentos para ruminantes que dão suporte à formulação de rações exigem que os alimentos sejam fracionados no sentido de melhor caracterizá-los. Os compostos nitrogenados são fracionados em: A (fração solúvel-NNP), $B_{1}$ (fração rapidamente degradada no rúmen), $\mathrm{B}_{2}$ (fração insolúvel, com taxa de degradação intermediária no rúmen), $\mathrm{B}_{3}$ (fração insolúvel, lentamente degradada no rúmen) e C ( fração insolúvel no rúmen e indigerível no intestino). Os carboidratos também são fracionados em: A (açúcares solúveis, com rápida degradação ruminal), $\mathrm{B}_{1}$ (amido e pectina), $\mathrm{B}_{2}$ (parede celular, com taxa de degradação mais lenta) e C (corresponde à fração nãodigerida ao longo de sua permanência no trato digestivo). Este fracionamento foi descrito por SNIFFEN et al. (1992), tendo como objetivo gerar dados para o sistema Cornell Net Carbohydrate and Protein System (CNCPS).
Objetivou-se, portanto, usar os dados observados sobre as variações nos teores de FDN, lignina e nas frações de carboidratos e as correspondentes taxas de degradação de 15 variedades de cana-de-açúcar, para avaliar a disponibilidade destes nutrientes em promover produção de leite de vacas holandesas mestiças usando o modelo CNCPS, versão 3.0.

\section{Material e Métodos}

Para se obterem as estimativas da produção de leite por vacas mestiças holandês-zebu, em função das diferentes variedade de cana-de-açúcar, foi utilizado o processo de simulação, por meio do modelo CNCPS para gado de leite, versão 3.0, de acordo com JUAREZ LAGUNES et al. (1999).

Os dados referentes às características das vacas, necessários para o "input" do sistema CNCPS, foram fornecidos pelo PDPL-RV (Programa de Desenvolvimento da Pecuária Leiteira - Região de Viçosa), realizado pelo convênio entre a Universidade Federal de Viçosa, Fundação Arthur Bernardes e Nestlé (Tabela 1).

As quinze variedades de cana-de-açúcar utilizadas (cana de ano ou 1 o corte) foram colhidas no campo experimental da Usina de Jatiboca, Município de Ponte Nova - MG.

$\mathrm{O}$ fracionamento dos carboidratos e a determinação das respectivas taxas de degradação da cana-deaçúcar, bem como as análises químicas, foram realizadas no Laboratório de Nutrição Animal do Departamento de Zootecnia da Universidade Federal de Viçosa - UFV.

Inicialmente, as amostras das variedades de canade-açúcar foram preparadas para determinar a matéria seca (MS), matéria mineral (MM), matéria orgânica (MO), proteína bruta (PB) e extrato etéreo (EE), seguindo os procedimentos padrões (ASSOCIATION OF OFFICIAL ANALYTICAL CHEMISTS - AOAC, 1990), e fibra em detergente neutro (FDN), ácido (FDA) e lignina (VAN SOEST et al., 1991).

Para obtenção do fracionamento dos carboidratos, conforme o sistema CNCPS, foram determinados os teores de nitrogênio total das amostras (NT), extrato etéreo e matéria mineral (AOAC, 1990). As frações dos carboidratos foram determinadas conforme SNIFFEN et al. (1992) e as taxas de degradação dos carboidratos fibrosos (CF) e carboidratos não-fibrosos (CNF), por intermédio da produção cumulativa de gás, conforme PELL e SCHOFIELD (1993). Os 
1352 Rev. bras. zootec.

Tabela 1 - Descrições do animal e do ambiente usadas pelo sistema CNCPS para avaliação das variedades de cana-deaçúcar

Table 1 - Animal and environment descriptions used in the CNCPS system to evaluate the sugar cane varieties

\begin{tabular}{|c|c|c|}
\hline $\begin{array}{l}\text { Descrição } \\
\text { Descrition }\end{array}$ & Input & $\begin{array}{l}\text { Unidades } \\
\text { Units }\end{array}$ \\
\hline Tipo de animal (Animal type) & 2 & Vacas em lactação (Lactating dairy cows) \\
\hline Idade $(A g e)$ & 66 & Mês (month) \\
\hline $\operatorname{Sexo}(\operatorname{Sex})$ & 4 & $\operatorname{Vaca}(\operatorname{cow})$ \\
\hline Peso corporal (Body weight) & 500 & $\mathrm{~kg}$ \\
\hline Tipo de raça (Breed type) & 2 & Mestiça (crossbred) \\
\hline Peso adulto (Mature weight) & 540 & $\mathrm{~kg}$ \\
\hline Escore corporal (Condition score) & 3 & 1 a 5 \\
\hline Sistema de cruzamento (Breeding system) & 2 & Tipo cruzamento (way cross) \\
\hline Raça da mãe (Dam's breed) & 15 & Holandesa (Holstein) \\
\hline Raça do pai (Bull's breed) & 17 & Zebu (Brahman) \\
\hline Dias de gestação (Days pregnant) & 40 & Dias (day) \\
\hline Dias de lactação (Days since calving) & 100 & Dias (day) \\
\hline $\mathrm{N}^{\circ}$ lactação (Lactation \#) & 4 & \\
\hline Média produção rebanho (Rolling herd average) & 2700 & $\mathrm{~kg}$ \\
\hline Produção de leite (Milk production) & 10 & $\mathrm{~kg} / \mathrm{d}$ \\
\hline Gordura leite (Milkfat) & 4 & $\%$ \\
\hline Proteína leite (Milk protein) & 3,2 & $\%$ \\
\hline Produção relativa leite (Relative milk production) & 5 & 1 a 9 \\
\hline Peso esperado bezerro (Expected calf birth weight) & 35 & $\mathrm{~kg}$ \\
\hline \multicolumn{3}{|l|}{ Descrição manejo (Management description) } \\
\hline Aditivo (Additive) & 1 & Nenhum (none) \\
\hline Tamanho área pasto (Grazing unit size) & 0 & Hectare \\
\hline Disponibilidade diária pasto (Daily pasture allowance) & 0 & $\begin{array}{l}\text { IMS }_{\text {atual }} / \text {IMS }_{\text {potencial }} \\
\left(D_{\text {(Dctual }} \text { DMI potential }\right.\end{array}$ \\
\hline Massa inicial pasto (Initial pature mass) & 0 & $\mathrm{~kg} / \mathrm{hectare}$ \\
\hline Freqüência alimentação (Feeding frequency) & 2 & $\mathrm{~N} \mathrm{O}$ vezes por dia (number of times per day) \\
\hline Métodos alimentação (Feeding method) & 2 & Mistura completa (total mixed ration) \\
\hline \multicolumn{3}{|l|}{ Descrição ambiente (Environmental description) } \\
\hline Velocidade vento (Wind speed) & 5 & $\mathrm{~kg} / \mathrm{h}$ \\
\hline Temperatura prevista (Previous temperature) & 25 & ${ }^{\circ} \mathrm{C}$ \\
\hline Temperatura atual (Current temperature) & 27 & ${ }^{\circ} \mathrm{C}$ \\
\hline Exposição chuva (Storm exposure) & 1 & $\operatorname{Sim}($ yes $)$ \\
\hline Queda de temperatura noturna (Night cooling) & 1 & Não (No cooling) \\
\hline Espessura pêlo (Hair depth) & 0,6 & $\mathrm{Cm}$ \\
\hline Couro (Hide) & 1 & Fino (thin) \\
\hline Animal ofegante (Cattle panting) & 1 & Nenhum (none) \\
\hline
\end{tabular}

dados oriundos das frações de carboidratos solúveis e da FDN foram interpretados pelo modelo bicompartimental $\mathrm{V}=\mathrm{Vf} 1 /(1+\exp (2-4 * \mathrm{C} 1 *(\mathrm{~T}-\mathrm{L})))+$ $\mathrm{Vf} 2 /(1+\exp (2-4 * \mathrm{C} 2 *(\mathrm{~T}-\mathrm{L})))$, em que Vf1 equivale ao volume máximo de gás da fração dos $\mathrm{CNF} ; \mathrm{C} 1$, à taxa de degradação $(\% / \mathrm{h})$ desta mesma fração $(\mathrm{CNF})$; Vf2, ao volume máximo de gás da fração dos $\mathrm{CF} ; \mathrm{C} 2$, à taxa de degradação $(\% / \mathrm{h})$ dos $\mathrm{CF} ; \mathrm{T}$ e L, aos tempos de incubação (horas) e a latência (horas), respectivamente, proposto por SCHOFIELD e PELL (1995). Para a realização dos ajustes, foi utilizado o processo interativo do algoritmo de Gauss Newton, utilizando-se o programa SAEG - Sistema de Análises Estatísticas e Genéticas (UNIVERSIDADE FEDERAL DE VIÇOSA - UFV, 2000).
Os dados referentes às taxas de degradação das frações protéicas B1, B2 e B3 da cana-de-açúcar, necessários ao "input" do sistema CNCPS, para o cálculo da degradabilidade dos alimentos, foram coletados do trabalho de PEREIRA et al. (2001). Portanto, tais análises não foram realizadas com as 15 variedades de cana-de-açúcar, em decorrência da pequena quantidade desses nutrientes nesta forrageira.

Os valores médio, máximo e mínimo das análises química e da cinética de degradação dos carboidratos das 15 variedades da cana-de-açúcar foram usados para predizer os efeitos das variações na composição desta forrageira sobre a produção de leite, usando o sistema CNCPS. Para gerar os "inputs" deste sistema, os seguintes valores foram avaliados: FDN, lignina, 
taxas de digestão dos carboidratos fibrosos (B2) e carboidratos não-fibrosos (A + B1).

Nestas avaliações, foi estabelecido um suplemento alimentar (silagem de milho, caroço de algodão, farelo de soja e uma mistura formada por nove partes de uréia uma parte de sulfato de amônio) para satisfazer as exigências nutricionais dos animais em produzirem $10 \mathrm{~kg}$ diário de leite, de acordo com o sistema CNCPS. A composição da dieta total (com base \% da matéria seca) foi constituída de: cana-deaçúcar $(6,2 \mathrm{~kg})$, silagem de milho $(2,0 \mathrm{~kg})$, caroço de algodão $(2,0 \mathrm{~kg})$, farelo de soja $(1,1 \mathrm{~kg})$ e uréia mais sulfato de amônio $(0,1 \mathrm{~kg})$, em que a cana-de-açúcar correspondeu a $75 \%$ do volumoso e a $54 \%$ da dieta. Estes alimentos que complementaram a dieta com a cana-de-açúcar, a fim de preencher as exigências nutricionais dos animais, foram escolhidos em função do uso dos mesmos pelos produtores de leite da região assistida pelo PDPL-RV, que fazem uso da cana-de-açúcar como principal volumoso, principalmente no período da estação de seca.

As variáveis de interesse para a interpretação dos resultados, fornecidas pelo sistema CNCPS, foram a quantidade de leite predita a partir daenergiametabolizável (EM) disponível para leite e proteína metabolizável (PM) disponível para leite, balanço de nitrogênio $(\mathrm{N})$ e balanço de peptídeo no rúmen, PM bacteriana e PM oriunda da proteína não-degradada no rúmen (PNDR).

\section{Resultados e Discussão}

1353

Os resultados principais das análises químicas e das taxas de degradação das 15 variedades da canade-açúcar são apresentados na Tabela 2.

Com base nos dados da Tabela 2, pode-se observar que o uso de outros alimentos com melhor qualidade nutricional faz-se necessário, quando a cana-de-açúcar é usada como principal volumoso em dietas de vacas leiteiras em produção, uma vez que todas as 15 variedades apresentaram baixo teor de proteína bruta e alto teor de carboidratos totais. Apesar de as variedades de cana-de-açúcar apresentarem elevada fração A (açúcares solúveis), o que, provavelmente, suportaria rápido crescimento microbiano no rúmen, as mesmas apresentaram baixa taxa de degradação ruminal da fibra potencialmente degradável (B2) com considerável efeito de repleção (PEREIRA et al., 2001), o que proporcionaria redução da ingestão de matéria seca e da disponibilidade de energia, limitando a produção desses animais (Tabela 3 ).

A forma de apresentação dos carboidratos nãofibrosos, como somatório de A e B1, baseia-se no aspecto de praticidade e analítico para efeito de cálculo de rações para ruminantes, uma vez que as metodologias de determinação do amido (B1), na maioria das vezes, não resultam em valores confiáveis e, portanto, não apresentam boa repetibilidade, em

Tabela 2 - Composição química, fracionamento dos carboidratos e suas taxas de degradação das variedades de cana-deaçúcar (\%MS) ${ }^{1}$

Table 2 - Chemical composition, carbohydrate fractions and their digestion rates of the sugar cane varieties (\% DM)

\begin{tabular}{lcccccccccccc}
\hline Variedade & MS & PB & EE & FDN & MM & Lig $^{2}$ & CT $^{3}$ & CNE & CE & \multicolumn{2}{c}{ C } & \multicolumn{2}{c}{ CNE $(\% / h)$} & CE $(\% / h)$ \\
Variety & $D M$ & $C P$ & Fat & NDF & Ash & Lig & TC & NSC & $S C$ & $C$ & $N S C$ & SC \\
\hline RB855113 & 29,5 & 2,6 & 0,74 & 49,7 & 1,4 & 11,9 & 95,3 & 48,7 & 36,4 & 14,9 & 19,5 \\
RB765418 & 29,1 & 2,6 & 0,69 & 50,0 & 1,5 & 12,6 & 95,2 & 48,2 & 35,9 & 15,9 & 18,6 \\
RB855536 & 27,0 & 3,2 & 0,72 & 47,3 & 1,5 & 13,5 & 94,6 & 50,8 & 33,0 & 16,2 & 22,1 \\
SP79-2233 & 27,7 & 3,0 & 0,65 & 45,7 & 1,6 & 13,5 & 94,7 & 52,6 & 31,7 & 15,7 & 19,3 \\
RB845257 & 28,1 & 2,4 & 0,72 & 48,8 & 1,4 & 13,2 & 95,5 & 49,7 & 34,1 & 16,2 & 18,4 \\
SP80-180 & 28,5 & 2,8 & 0,68 & 48,8 & 1,3 & 13,4 & 95,3 & 49,6 & 33,9 & 16,5 & 18,4 \\
RB855453 & 28,5 & 2,7 & 0,68 & 51,2 & 1,8 & 12,8 & 94,8 & 46,8 & 36,6 & 16,6 & 18,9 \\
RB855336 & 29,4 & 2,8 & 0,67 & 49,4 & 1,9 & 13,1 & 94,6 & 48,6 & 35,0 & 16,4 & 17,7 \\
SP80-1842 & 29,3 & 2,9 & 0,70 & 46,6 & 1,2 & 14,9 & 95,2 & 51,8 & 30,8 & 17,5 & 17,4 \\
SP81-1763 & 27,7 & 2,5 & 0,72 & 46,5 & 1,6 & 13,9 & 95,2 & 52,0 & 31,9 & 16,2 & 18,3 \\
SP80-4445 & 26,9 & 2,5 & 0,70 & 45,2 & 1,6 & 12,6 & 95,2 & 53,3 & 32,4 & 14,3 & 18,6 \\
SP79-1011 & 19,1 & 2,2 & 0,67 & 47,2 & 1,5 & 13,0 & 95,7 & 51,3 & 33,3 & 15,3 & 16,2 & 2,2 \\
RB739359 & 27,5 & 2,5 & 0,68 & 44,8 & 1,8 & 14,4 & 95,0 & 53,6 & 30,1 & 16,3 & 18,1 \\
RB867515 & 28,9 & 2,9 & 0,70 & 47,9 & 1,6 & 13,8 & 94,8 & 50,3 & 33,0 & 16,7 & 19,3 \\
SP80-3280 & 27,4 & 2,7 & 0,64 & 49,8 & 1,7 & 13,5 & 94,8 & 48,4 & 34,7 & 16,9 & 18,2
\end{tabular}

1 Dados obtidos a partir das médias para cada nutriente, das variedades de cana-de-açúcar.

2 Lig = lignina como porcentagem da fibra em detergente neutro (FDN).

$3 \mathrm{CT}=$ carboidratos totais [100-(PB+EE+MM)].

1 Data obtained from the averages for each nutrient of the sugar cane varieties.

2 Lign = lignin as percentage of the neutral detergent fiber.

${ }^{3}$ TC $=$ total carbohydrates $[100-(C P+F a t+$ Ash $)]$. 
1354 Rev. bras. zootec.

Tabela 3 - Comparação entre a cana-de-açúcar como único alimento e a dieta básica total quanto à capacidade em atender as exigências nutricionais de vacas leiteiras mestiças holandeas, com média de $500 \mathrm{~kg}$ PV e produção de $10 \mathrm{~kg}$ leite/dia, de acordo com o sistema CNCPS

Table 3 - Comparison among the sugar cane fed alone and the total basal diet with relation to the ability to support the nutritional requirements of Holstein dairy cows, with average $500 \mathrm{~kg} \mathrm{LW}$ and $10 \mathrm{~kg} /$ day of milk production, in accordance with CNCPS system

\begin{tabular}{cc}
\hline Cana-de- & Dieta básica \\
açúcar $^{1}$ & total $^{2}$ \\
Sugar cane & Total basal diet
\end{tabular}

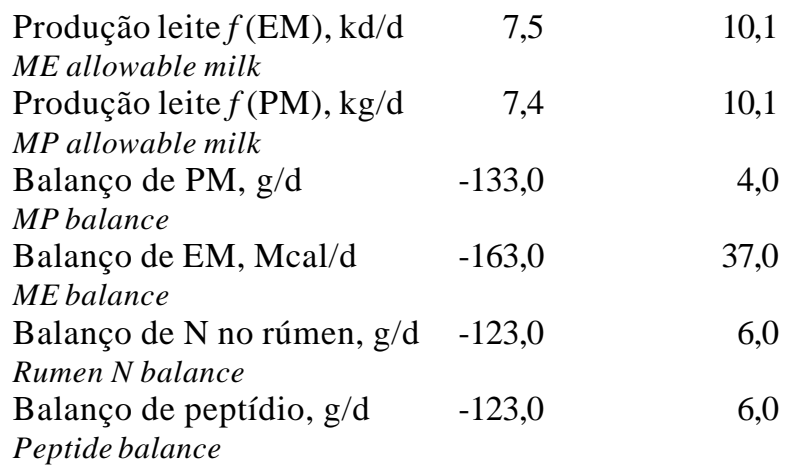

${ }^{1}$ Assumiu-se o consumo de cana-de-açúcar de $11,4 \mathrm{~kg} / \mathrm{d}$, correspondendo a $100 \%$ da MS.

${ }^{2}$ A cana-de-açúcar correspondeu a $54 \%$ da dieta total e a $75 \%$ do volumoso, sendo fixado um consumo constante de matéria seca igual a $11,4 \mathrm{~kg} / \mathrm{d}$, de acordo com o sistema CNCPS.

${ }^{1} A$ intake of sugar cane of $11.4 \mathrm{~kg} / \mathrm{d}$ was assumed, corresponding to $100 \%$ of the $D M$.

${ }^{2}$ The sugar cane corresponded to $54 \%$ of the total diet and $75 \%$ of the forage, being fixed a constant dry matter intake equal to $11.4 \mathrm{~kg} / \mathrm{day}$, in accordance with the CNCPS system.

função da natureza heterogênea dos tecidos vegetais (MALAFAIA et al., 1997).

Para predizer as respostas na produção de leite, em função das mudanças na composição química, no fracionamento e taxa de degradação dos carboidratos das variedades de cana-de-açúcar, de acordo com o sistema CNCPS, foram usados os valores mínimo, médio e máximo aproximados, observados nestas análises. Estes valores foram, respectivamente: FDN (\% MS) - 40, 50 e 60, lignina (\% FDN) - 10, 14 e 18; taxas de digestão $(\% / \mathrm{h}) \operatorname{dos} \mathrm{CNF}(\mathrm{A}+\mathrm{B} 1)-10,20$ e 30 e taxa de digestão $(\% / h)$ dos CF (B2) - 1, 2,5 e 4, e encontram-se na Tabela 4.

\section{Fibra em detergente neutro e lignina}

Os resultados apresentados pelo sistema CNCPS, em função das mudanças nas concentrações de FDN e lignina, constam da Tabela 5 .

Observa-se que, com a concentração intermediária de lignina (14\%), a produção de leite esperada em função da EM decresceu 24\%, quando o valor da FDN aumentou de 40 para $60 \%$. A redução esperada na produção de leite foi devida à diminuição dos carboidratos não-estruturais e ao aumento dos carboidratos estruturais. A PM microbiana diminuiu 19\%, em decorrência de menor disponibilidade ruminal de carboidratos; conseqüentemente, a produção esperada de leite em função da PM reduziu em $37 \%$. $\mathrm{O}$ balanço de $\mathrm{N}$ no rúmen aumentou devido ao menor crescimento microbiano, ou seja, não houve sincronismo entre a disponibilidade de carbono e de nitrogênio no rúmen para permitir máxima eficiência microbiana.

Na concentração intermediária de FDN (50\%), o aumento na concentração de lignina de 14 para $18 \%$ causou diminuição de $7 \%$ na produção esperada de leite, em função da EM, porque a elevação nos teores de lignina reduziu a disponibilidade dos carboidratos estruturais. A PM microbiana foi reduzida em 3\%, diminuindo a produção de leite, em função da PM, em 10\%. Novamente, o balanço de $\mathrm{N}$ no rúmen aumentou, porque houve menor crescimento microbiano, o que pode ser verificado pela redução do balanço de PM microbiana e pela não variação na quantidade de PM oriunda da PNDR.

À medida que se diminuiu o teor de FDN, ou seja, aumentou o teor de CNF, diminuíram os balanços de $\mathrm{N}$ e peptídeos, porque aumentou a disponibilidade de energia e, com isso, a utilização de $\mathrm{N}$ e peptídeo no rúmen, o que pode ser confirmado pelo aumento da PM microbiana. Neste caso, o crescimento microbiano pode estar sendo limitado pelo déficit em peptídeo. Portanto, a adição de proteína verdadeira à dieta poderá ser benéfica, conforme VAN SOEST (1994), justificando o uso de alimentos com tais características, quando se utiliza a cana-de-açúcar como principal volumoso para vacas em lactação.

\section{Carboidratos - taxas de digestão}

As variações apresentadas pelo sistema CNCPS para as mudanças nas taxas de digestão dos carboidratos constam da Tabela 6 .

A produção esperada de leite, em função da EM e PM disponíveis, não sofreu alterações pelas mudanças na taxa de digestão dos carboidratos nãoestruturais (fração $A+B 1$ ), em virtude desta fração ser totalmente degradada no rúmen, mesmo na menor taxa de digestão $(10 \% / \mathrm{h})$.

Entretanto, a produção esperada de leite, em função da EM e PM, foi sensível às mudanças na taxa de digestão da fração B2 dos carboidratos, quando a taxa de digestão dos CNE foi mantida constante $(2,5 \% / \mathrm{h})$. A produção esperada de leite em função da EM aumentou 14\%, quando a taxa de digestão foi aumentada de 1 para $2,5 \%$, e aumento 
FERNANDES et al.

Tabela 4 - Valores máximo, médio e mínimo da composição química, fracionamento dos carboidratos e suas taxas de degradação, das variedades de cana-de-açúcar $(\% \mathrm{MS})^{1}$

Table 4 - Values of maximum, medium and minimum of the chemical composition carbohydrate fractions and their digestion rates of the sugar cane varieties (\% DM)

\begin{tabular}{|c|c|c|c|c|c|c|c|c|c|c|c|c|}
\hline & $\begin{array}{l}\text { MS } \\
D M\end{array}$ & $\begin{array}{l}\mathrm{PB} \\
C P\end{array}$ & $\begin{array}{l}\mathrm{EE} \\
\text { Fat }\end{array}$ & $\begin{array}{l}\text { FDN } \\
N D F\end{array}$ & $\begin{array}{l}\mathrm{MM} \\
\text { Ash }\end{array}$ & $\begin{array}{c}\mathrm{Lig}^{2} \\
\mathrm{Lig}\end{array}$ & $\begin{array}{c}\mathrm{CT}^{3} \\
T C\end{array}$ & $\begin{array}{l}\mathrm{CNE} \\
N S C\end{array}$ & $\begin{array}{l}\mathrm{CE} \\
S C\end{array}$ & $\begin{array}{l}\mathrm{C} \\
\mathrm{C}\end{array}$ & $\begin{array}{c}\mathrm{CNE}(\% / \mathrm{h}) \\
N S C\end{array}$ & $\begin{array}{c}\mathrm{CE}(\% / \mathrm{h}) \\
\mathrm{SC}\end{array}$ \\
\hline $\begin{array}{l}\text { Máximo } \\
\text { Maximum }\end{array}$ & 32,0 & 3,7 & 0,86 & 58,6 & 2,78 & 17,7 & 96,0 & 55,9 & 41,3 & 20,6 & 30,0 & 3,8 \\
\hline $\begin{array}{l}\text { Médio } \\
\text { Medium }\end{array}$ & 28,3 & 2,7 & 0,69 & 47,9 & 1,56 & 13,4 & 95,0 & 50,4 & 33,5 & 16,1 & 18,6 & 2,3 \\
\hline $\begin{array}{l}\text { Mínimo } \\
\text { Minimum }\end{array}$ & 25,0 & 1,7 & 0,46 & 42,7 & 0,91 & 10,1 & 93,7 & 42,2 & 26,1 & 12,7 & 10 & 1,0 \\
\hline
\end{tabular}

${ }_{1}^{1}$ Dados obtidos a partir das médias para cada nutriente, das variedades de cana-de-açúcar.

${ }^{2}$ Lig = Lignina como porcentagem da fibra em detergente neutro (FDN).

${ }^{3} \mathrm{CT}=$ Carboidratos totais $[100-(\mathrm{PB}+\mathrm{EE}+\mathrm{MM})]$.

${ }^{1}$ Data obtained from the averages for each nutrient of the sugar cane varieties.

${ }^{2}$ Lign = Lignin as percentage of the neutral detergent fiber.

${ }^{3} \mathrm{TC}=$ Total carbohydrates $[100-(C P+F a t+A s h)]$.

Tabela 5 - Respostas esperadas na produção de leite e parâmetros ruminais, em função das mudanças nos teores de FDN e lignina das variedades de cana-de-açúcar ${ }^{1,2}$

Table 5 - Expected milk production responses and ruminal parameter, according to changes in NDF and lignin contents of the sugar cane varieties

\begin{tabular}{|c|c|c|c|c|c|c|c|c|c|}
\hline \multirow[t]{3}{*}{ Item } & \multicolumn{3}{|c|}{$40 \% \mathrm{FDN}^{3}$} & \multicolumn{3}{|c|}{$50 \% \mathrm{FDN}$} & \multicolumn{3}{|c|}{$60 \% \mathrm{FDN}$} \\
\hline & $10 \%$ & $14 \%$ & $18 \%$ & $10 \%$ & $14 \%$ & $18 \%$ & $10 \%$ & $14 \%$ & $18 \%$ \\
\hline & & & & & & & & & \\
\hline $\begin{array}{l}\text { Produção leite } f(\mathrm{EM}), \mathrm{kd} / \mathrm{d} \\
\text { ME allowable milk }\end{array}$ & 11,8 & 11,3 & 10,8 & 10,7 & 10,1 & 9,4 & 9,5 & 8,6 & 7,7 \\
\hline $\begin{array}{l}\text { Produção leite } f(\mathrm{PM}), \mathrm{kg} / \mathrm{d} \\
\text { MP allowable milk }\end{array}$ & 12,8 & 12,3 & 11,9 & 10,6 & 10,1 & 9,5 & 8,4 & 7,8 & 7,1 \\
\hline $\begin{array}{l}\text { Balanço de } \mathrm{PM}, \mathrm{g} / \mathrm{d} \\
\text { MP balance }\end{array}$ & 140,0 & 119,0 & 98,0 & 31,0 & 4,0 & $-23,0$ & $-79,0$ & $-112,0$ & $-146,0$ \\
\hline $\begin{array}{l}\text { Balanço de EM, Mcal/d } \\
\text { ME balance }\end{array}$ & 2,1 & 1,5 & 0,9 & 0,9 & 0,1 & $-0,7$ & $-0,6$ & $-1,6$ & $-2,6$ \\
\hline $\begin{array}{l}\text { Balanço de } \mathrm{N} \text { no rúmen, } \mathrm{g} / \mathrm{d} \\
\text { Rumen } N \text { balance }\end{array}$ & 13,0 & 15,0 & 17,0 & 34,0 & 37,0 & 40,0 & 56,0 & 60,0 & 63,0 \\
\hline $\begin{array}{l}\text { Balanço de peptídio, g/d } \\
\text { Peptide balance }\end{array}$ & $-12,0$ & $-12,0$ & $-12,0$ & 6,0 & 6,0 & 6,0 & 24,0 & 24,0 & 24,0 \\
\hline $\begin{array}{l}\text { PM microbiano, } \mathrm{g} / \mathrm{d} \\
\text { PM from bacteria }\end{array}$ & 872 & 863 & 840 & 792 & 781 & 769 & 710 & 696 & 682 \\
\hline $\begin{array}{l}\text { PM oriunda da PNDR, } \mathrm{g} / \mathrm{d} \\
M P \text { from UIP }\end{array}$ & 281 & 281 & 281 & 280 & 280 & 280 & 279 & 279 & 279 \\
\hline
\end{tabular}

${ }^{1}$ A cana-de-açúcar correspondeu a $54 \%$ da dieta total e a $75 \%$ do volumoso, sendo fixado um consumo constante de matéria seca igual a $11,4 \mathrm{~kg} / \mathrm{d}$, de acordo com o sistema CNCPS.

2 Valores médio, máximo e mínimo absolutos das análises química e da cinética de degradação dos carboidratos das 15 variedades da cana-de-açúcar.

3 FDN - porcentagem da matéria seca.

4 Lignina - porcentagem da FDN.

1 The sugar cane corresponded to $54 \%$ of the total diet and $75 \%$ of the forage, being fixed a constant dry matter intake equal to $11.4 \mathrm{~kg} / \mathrm{d}$, in accordance with CNCPS system.

2 Absolute medium, maximum and minimum values of the chemical and kinetics analysis of the carbohydrate degradation of 15 sugar cane varieties.

${ }^{3} \mathrm{NDF}$ - percentage of the dry matter.

4 Lignin-percentage of the NDF.

adicional de $7 \%$ foi obtido quando esta taxa foi elevada de 2,5 para $4 \% / \mathrm{h}$.

A produção esperada de leite, em função da $\mathrm{PM}$, aumentou de 8,4 para $10,1 \mathrm{~kg} / \mathrm{d}$, com incremento de 1 para $2,5 \% / \mathrm{h}$ na taxa de degradação de B2, e acrescida para $11,3 \mathrm{~kg} / \mathrm{d}$, com aumento nesta mesma taxa de 2,5 para $4 \% / \mathrm{h}$. Estes aumentos foram o resultado de maior degradação ruminal dos carboidratos estruturais, promovendo maior crescimento microbiano, o que pode ser comprovado pela diminuição do balanço de $\mathrm{N}$ no rúmen e pelo aumento da PM microbiana, à medida que se aumenta a taxa de degradação de B2. A fração B2 (CF) da cana-de-açúcar foi, portanto, a que mais afetou a disponibilidade de energia para a predição da produção de leite, estando estes resultados de 
1356 Rev. bras. zootec.

Tabela 6 - Respostas esperadas na produção de leite e parâmetros ruminais, em função das mudanças nas taxas de digestão dos carboidratos das variedades de cana-de-açúcar ${ }^{1,2}$

Table 6 - Expected milk production responses and ruminal parameters, according to changes in the carbohydrate digestion rates of the sugar cane varieties

\begin{tabular}{|c|c|c|c|c|c|c|c|c|c|}
\hline \multirow[t]{2}{*}{ Item } & \multicolumn{3}{|c|}{$\mathrm{A}+\mathrm{B}_{1} 10 \% / \mathrm{h}$} & \multicolumn{3}{|c|}{$\mathrm{A}+\mathrm{B}_{1} 20 \% / \mathrm{h}$} & \multicolumn{3}{|c|}{$\mathrm{A}+\mathrm{B}_{1} 30 \% / \mathrm{h}$} \\
\hline & $\begin{array}{c}\mathrm{B}_{2} \\
1 \% / \mathrm{h}\end{array}$ & $\begin{array}{c}\mathrm{B}_{2} \\
2,5 \% / \mathrm{h}\end{array}$ & $\begin{array}{c}\mathrm{B}_{2} \\
4 \% / \mathrm{h}\end{array}$ & $\begin{array}{l}\mathrm{B}_{2} \\
1 \% / \mathrm{h}\end{array}$ & $\begin{array}{c}\mathrm{B}_{2} \\
2,5 \% / \mathrm{h}\end{array}$ & $\begin{array}{c}\mathrm{B}_{2} \\
4 \% / \mathrm{h}\end{array}$ & $\begin{array}{c}\mathrm{B}_{2} \\
1 \% / \mathrm{h}\end{array}$ & $\begin{array}{c}\mathrm{B}_{2} \\
2,5 \% / \mathrm{h}\end{array}$ & $\begin{array}{c}\mathrm{B}_{2} \\
4 \% / \mathrm{h}\end{array}$ \\
\hline $\begin{array}{l}\text { Produção leite } f(\mathrm{EM}), \mathrm{kd} / \mathrm{d} \\
\text { ME allowable milk }\end{array}$ & 8,7 & 10,1 & 10,8 & 8,7 & 10,1 & 10,8 & 8,7 & 10,1 & 10,8 \\
\hline $\begin{array}{l}\text { Produção leite } f(\mathrm{PM}), \mathrm{kg} / \mathrm{d} \\
\text { MP allowable milk }\end{array}$ & 8,3 & 10,0 & 11,2 & 8,4 & 10,1 & 11,3 & 8,5 & 10,1 & 11,3 \\
\hline $\begin{array}{l}\text { Balanço de PM, g/d } \\
\text { MP balance }\end{array}$ & $-84,0$ & $-1,0$ & 60,0 & $-80,0$ & 4,0 & 64,0 & $-78,0$ & 6,0 & 66,0 \\
\hline $\begin{array}{l}\text { Balanço de EM, Mcal/d } \\
\text { ME balance }\end{array}$ & $-1,5$ & 0,1 & 0,9 & $-1,5$ & 0,1 & 0,9 & $-1,5$ & 0,1 & 0,9 \\
\hline $\begin{array}{l}\text { Balanço de } \mathrm{N} \text { no rúmen, } \mathrm{g} / \mathrm{d} \\
\text { Rumen } N \text { balance }\end{array}$ & 52,0 & 38,0 & 27,0 & 51,0 & 37,0 & 26,0 & 51,0 & 37,0 & 25,0 \\
\hline $\begin{array}{l}\text { Balanço de peptídio, g/d } \\
\text { Peptide balance }\end{array}$ & 6,0 & 6,0 & 6,0 & 6,0 & 6,0 & 6,0 & 5,0 & 5,0 & 5,0 \\
\hline $\begin{array}{l}\mathrm{PM} \text { microbiano, } \mathrm{g} / \mathrm{d} \\
\text { PM from bacteria }\end{array}$ & 723 & 776 & 818 & 728 & 781 & 823 & 730 & 783 & 825 \\
\hline $\begin{array}{l}\mathrm{PM} \text { oriunda da } \mathrm{PNDR}, \mathrm{g} / \mathrm{d} \\
\text { MP from UIP }\end{array}$ & 280 & 280 & 280 & 280 & 280 & 280 & 280 & 280 & 280 \\
\hline
\end{tabular}

${ }^{1}$ A cana-de-açúcar correspondeu a $54 \%$ da dieta total e a $75 \%$ do volumoso, sendo fixado um consumo constante de matéria seca igual a $11,4 \mathrm{~kg} / \mathrm{d}$, de acordo com o sistema CNCPS.

2Valores médio, máximo e mínimo absolutos das análises química e da cinética de degradação dos carboidratos das 15 variedades da canade-açúcar.

${ }^{1}$ The sugar cane corresponded to $54 \%$ of the total diet and $75 \%$ of the forage, being fixed a constant dry matter intake equal to $11.4 \mathrm{~kg} / \mathrm{d}$, in accordance with the CNCPS system.

${ }^{2}$ Absolute medium, maximum and minimum values of the chemical and kinetics analysis of the carbohydrate degradation of 15 sugar cane varieties.

acordo com VAN SOEST (1994), que caracterizou a respectiva fração como a mais variável quanto à sua disponibilidade no TGI.

Mudanças nas rações de vacas leiteiras, em função dos diferentes teores de FDN e lignina da cana-de-açúcar

Houve considerável variação nos percentuais de FDN e lignina nas diferentes variedade da cana-deaçúcar, como observado na Tabela 2. Estas variações conferem diferenças importantes entre estes alimentos, podendo afetar o consumo destes pelos animais, uma vez que a relação entre a FDN e o consumo é negativa (MERTENS, 1987). Em virtude de a lignina ser o componente da parede celular vegetal que mais afeta a disponibilidade dos polissacarídeos fibrosos, o aumento da sua concentração na FDN obrigatoriamente reduz a disponibilidade de energia dos alimentos (VAN SOEST, 1994).

Para se formularem rações com a finalidade de observar as variações ocorridas na produção de leite, em função dos diferentes teores de FDN e lignina, das variedades de cana-de-açúcar, a variável de interesse para a interpretação dos resultados fornecidos pelo sistema CNCPS foi produção de leite, em função da EM e PM disponíveis na dieta. Os resultados das variações destes nutrientes sobre a composição das rações constam da Tabela 7 .

Observa-se que, com a concentração intermediária de FDN (50\%), aumento no percentual da lignina de 14 para $18 \%$ causou diminuição de 9,8\% na quantidade de volumoso fornecido, ou seja, aumento de $800 \mathrm{~g}$ no fornecimento de concentrado/ animal/dia. Todavia, houve diminuição na necessidade de concentrado, na mesma quantidade, quando o valor da lignina diminuiu de 14 para $10 \%$.

Entretanto, comparando-se o mesmo teor de lignina (14\%), porém com os diferentes percentuais de FDN, nota-se que as necessidades de concentrado foram de 1,6; 3,2 e 4,6 kg/d, para os valores percentuais de FDN da cana-de-açúcar de 40, 50 e $60 \%$, respectivamente, predito pelo sistema CNCPS, para manter a mesma produção de leite $(10 \mathrm{~kg} / \mathrm{d})$.

$\mathrm{O}$ aumento na concentração de FDN e lignina da cana-de-açúcar foi acompanhado pela redução deste alimento na dieta, ou seja, houve maior necessidade de suprimento de energia e, conseqüentemente, maior necessidade de concentrado na dieta, diminuindo a relaçãovolumo:concentrado, preditopelo sistemaCNCPS. 
FERNANDES et al.

Tabela 7 - Rações para vacas holandesas mestiças com $500 \mathrm{~kg}$ PV e produção de $10 \mathrm{~kg}$ leite/dia, de acordo com o CNCPS, função das variações dos teores de FDN e lignina das variedades de cana-de-açúcar ${ }^{1,2}$.

Table 7 - Diets for crossbred Holstein cows with $500 \mathrm{~kg} L W$ and $10 \mathrm{~kg} / \mathrm{d}$ of milk production, in accordance with CNCPS, in function of the changes of the FDN and lignin content of the sugar cane varieties

\begin{tabular}{|c|c|c|c|c|c|c|c|c|c|}
\hline \multirow[t]{3}{*}{ Item } & \multicolumn{3}{|c|}{$40 \% \mathrm{FDN}^{3}$} & \multicolumn{3}{|c|}{$50 \% \mathrm{FDN}$} & \multicolumn{3}{|c|}{$60 \% \mathrm{FDN}$} \\
\hline & $\begin{array}{l}10 \% \\
-4\end{array}$ & $14 \%$ & $18 \%$ & $10 \%$ & $14 \%$ & $18 \%$ & $10 \%$ & $14 \%$ & $18 \%$ \\
\hline & & & & & & & & & \\
\hline \multicolumn{10}{|c|}{ Consumo de MS (kg/dia) } \\
\hline \multicolumn{10}{|c|}{ Intake ( $\mathrm{kg} /$ day) } \\
\hline Cana-de-açúcar & 11,2 & 8,8 & 8,5 & 7,0 & 6,2 & 6,7 & 7,3 & 6,0 & 5,0 \\
\hline \multicolumn{10}{|l|}{ Sugar cane } \\
\hline Silagem de milho & 0,0 & 1,0 & 0,0 & 2,0 & 2,0 & 0,7 & 0,5 & 0,8 & 0,0 \\
\hline \multicolumn{10}{|l|}{ Corn silage } \\
\hline Caroço de algodão & 0,0 & 1,4 & 2,6 & 1,5 & 2,0 & 2,7 & 2,0 & 2,5 & 3,8 \\
\hline \multicolumn{10}{|l|}{ Whole cottonseed } \\
\hline Farelo de soja & 0,0 & 0,0 & 0,1 & 0,8 & 1,1 & 1,3 & 1,6 & 2,1 & 2,6 \\
\hline \multicolumn{10}{|l|}{ Soybean meal } \\
\hline Uréia & 0,2 & 0,2 & 0,2 & 0,1 & 0,1 & 0,0 & 0,0 & 0,0 & 0,0 \\
\hline Urea & & & & & & & & & \\
\hline
\end{tabular}

${ }^{1}$ Foi estabelecido um consumo constante de matéria seca igual a $11,4 \mathrm{~kg} / \mathrm{d}$, de acordo com o sistema CNCPS.

2 Valores médio, máximo e mínimo absolutos das análises química e da cinética de degradação dos carboidratos das 15 variedades da cana-de-açúcar.

3 FDN - porcentagem da matéria seca.

4 Lignina - porcentagem da FDN.

1 It was established a constant dry matter intake equal to $11,4 \mathrm{~kg} / \mathrm{d}$, in accordance with CNCPS system.

2 Absolute medium, maximum and minimum values of the chemical and kinetics analysis of the carbohydrate degradation of 15 sugar cane varieties.

${ }^{3} \mathrm{NDF}$ - percentage of the dry matter.

${ }^{4}$ Lignin - percentage of the NDF.

\section{Conclusões}

As variações nas frações de carboidratos e nas taxas de degradação dos mesmos, das diferentes variedades de cana-de-açúcar, têm grande efeito sobre a produção de leite das vacas mestiças.

A fibra é a fração que mais afeta o desempenho animal. Portanto, a sua elevação na cana-de-açúcar acarretou aumento da necessidade de suplementação de concentrado na dieta e, conseqüentemente, aumento dos custos.

Embora os dados apresentados nesta pesquisa permitam visualizar os efeitos decorrentes das alterações das frações de carboidratos no desempenho animal, torna-se necessária sua validação, ou seja, a comparação entre os valores observados e preditos de produção de leite.

\section{Referências Bibliográficas}

ASSOCIATION OF OFFICIAL ANALYTICAL CHEMISTS AOAC. 1990. Official methods of analysis. 15.ed., Virginia: Arlington. $1117 \mathrm{p}$.

JUAREZ LAGUNES, F.I., FOX, D.G., BLAKE, R.W. et al. 1999. Evalution of tropical grasses for milk. Production by dual-purpose cows in tropical Mexico. J. Dairy Sci., 82(10):2136-2145.

LENG, R. A. 1988. Limitaciones metabolicas en la utilización de la caña de azúcar y sus derivados para el crecimiento y producción de leche en ruminantes. In: PRESTON, T.R.,
ROSALES, M. (Eds.) Siculmas intensivos para la producción animal y energia renovable con recursos tropicales. Cali: CIPAV. p.1-24.

MALAFAIA, P.A.M. VIEIRA, R.A.M. Técnicas de determinação e avaliação dos componentes nitrogenados em alimentos para rumiantes. In: SIMPÓSIO INTERNACIONAL DE DIGESTIBILIDADE EM RUMINANTES, Lavras, 1997. Anais... Lavras: FAEPE, 1997. p.29-54.

MERTENS, D.R. 1987. Predicting intake and digestibility using mathematical models of ruminal function. J. Anim. Sci., 64(8):1584-1558.

MERTENS, D.R. 1997. Creating a system for meeting the fiber requirements of dairy cows. J. Dairy Sci., 80(8):1463-1469.

PATE, F.M. 1977. Nutritive value of sugar cane at different stages of maturity. Trop. Anim. Prod., 2(1):108 (abstracts).

PELL, A.N., SCHOFIELD, P. 1993. Computerized monitoring of gas production to measure forage digestion in vitro. J. Dairy Sci., 76(9):1063-1073.

PEREIRA, E.S., QUEIROZ, A.C., PAULINO, M.F. et al. 2001. Fontes nitrogenadas e uso de Sachoromyces cerevisiae em dietas à base de cana-de-açúcar para novilhos: consumo, digestibilidade, balanço nitrogenado e parâmetros ruminais. 30(2):563-572.

SCHOFIELD, P. PELL, A.N. 1995. Measurement and kinetic analysis of the neutral detergent-soluble carbohydrate fraction of legumes and grasses. J. Anim. Sci., 73(4):3455-3463.

SNIFFEN, C.J., O'CONNOR, J.D., VAN SOEST, P.J. et al. 1992. A net carbohydrate and protein system for evaluating cattle diets. II. Carbohydrate and protein availability. J. Anim. Sci., 70(7):3562-3577.

VAN SOEST, P.J. 1994. Nutritional ecology of the ruminant. 2.ed. New York: Cornell University Press. Ithaca. 476p.

Recebido em: 03/11/00 Aceito em: 02/03/01 